\title{
A dimensão jurídica da sustentabilidade à luz dos trinta anos da Constituição federal ${ }^{1}$
}

\author{
The legal dimension of sustainability in the light of the thirty years of the \\ federal Constitution
}

La dimensiónjurídica de la sostenibilidad a la luz de los treinta años de la Constitución federal

Sérgio Ricardo Fernandes de Aquino*

\section{Resumo}

Este estudo trata sobre a importância da sustentabilidade e seu significado jurídico nesses trinta anos de vigência da Constituição federal de 1988. O objetivo é demonstrar como a definição de sustentabilidade em sua dimensão jurídica favorece a histórica compreensão sobre as relações entre humanos e não humanos e a necessária exigibilidade de ações que prejudicam o aperfeiçoamento dessa perspectiva harmônica. $\mathrm{Na}$ fase de investigação, utilizou-se o método indutivo. Conclui-se que houve avanços na aplicação do artigo 225 da Constituição, mas que o século XXI traz novos desafios ainda pouco compreendidos pela semântica constitucional.

Palavras-chave: Constituição federal de 1988. Desafios. Dimensão jurídica. Sustentabilidade. Trinta anos.

\section{Introdução}

Há certo sentido metafísico na sustentabilidade, o que não a permite impulsionar, com maior vigor e impacto, os projetos civilizacionais propostos à arquitetura ecológica, no sentido da nossa "Casa Comum", do século XXI.

Enrique Leff (2015, p. 413), ao enfatizar a importância da sustentabilidade, enuncia que a mensagem dessa palavra é o anúncio de um tempo que não é. Ao que parece, tem-

Doutor em Ciência Jurídica pela Universidade
do Vale do Itajaí (2013). Professor permanente do
Programa de Pós-Graduação em Direito (PPGD)
- Mestrado, da Faculdade Meridional (Imed). Co-
ordenador do grupo de pesquisa Ética, Cidadania
e Sustentabilidade, do PPGD da Imed. E-mail:
sergiorfaquino@gmail.com

Recebido em 28/5/2018 - Aprovado em 25/6/2018 http://dx.doi.org/10.5335/hdtv.18n.3.8594 
-se, exatamente, uma proposta de utopias para a sustentabilidade se tornar "de carne e osso", e talvez isto seja o que ainda não foi compreendido: sustentabilidade é sempre um porvir, é aquilo que se almeja a fim de traduzir anseios, receios, relações e modos de superação de dificuldades, em: a) humanizar o humano; e b) como essa condição ocorre a partir daquilo que a natureza revela às nossas consciências.

Analisando-se a sustentabilidade a partir dessas premissas, apresenta-se o seguinte problema de pesquisa deste estudo: quais são os avanços sobre a efetividade da sustentabilidade em sua dimensão jurídica nesses trinta anos de vigência da Constituição federal de 1988?

Como hipótese, que visa responder provisoriamente essa indagação, pode ser observada uma adequação do direito às súplicas do momento presente, de modo a conduzir um aprofundamento teórico a respeito da sustentabilidade. Entretanto, tem-se verificado, ao mesmo tempo, um desvio prático dessa categoria, que passa a ser permeada por discursos ideológicos, conduzindo a uma redução dos resultados pretendidos.

Como objetivo geral, procura-se demonstrar como a definição de sustentabilidade em sua dimensão jurídica favorece a histórica compreensão sobre as relações entre humanos e não humanos e a necessária exigibilidade de ações que prejudicam o aperfeiçoamento dessa perspectiva harmônica. Além disso, elencam-se os seguintes objetivos específicos: a) expor um panorama da sustentabilidade, a partir dos trinta anos da Constituição federal; b) apresentar alguns fundamentos e a definição da sustenta- bilidade, especialmente no âmbito jurídico; c) identificar os avanços da sustentabilidade nos trinta anos da Constituição federal de 1988.

Para o desenvolvimento deste trabalho, conta-se com o método de pesquisa indutivo. A viabilização do método ocorre por meio das seguintes técnicas de pesquisa: pesquisa bibliográfica e documental, ${ }^{2}$ categoria $^{3}$ e conceito operacional. ${ }^{4}$

\section{Trinta anos de conquistas: a força da Constituição de 1988}

A Constituição federal brasileira de 1988 nasce da transição de um Estado ditatorial e intolerante para um Estado democrático de direito e, ainda, inaugura uma mudança de paradigma, em que o direito deixa de ser um mero instrumento voltado à organização da vida econômica e administrativa e passa a estruturar e regular as mais diversas esferas, tal como a social e a do meio ambiente (BENJAMIN, 2011).

No entanto, nos últimos quatro anos, a intensificação da crise institucional mostrou não apenas a indiferença de determinados segmentos sociais com a efetividade dos direitos fundamentais, especialmente dos sociais, mas, também, a transformação da lei num instrumento de eficácia ideológica, ou seja, o sentido e o resultado da lei emanam da vontade do legislador e do magistrado sem nenhum apreço pelas regras formais e os conteúdos materiais expostos no ordenamento jurídico. Vive-se, hoje, um acentuado retrocesso político e jurídico, causando a insegurança entre todos os cidadãos. 
Não obstante esse cenário de desvalorização dos bens constitucionalmente tutelados, verifica-se a sensibilidade social, ética e jurídica da Constituição de 1988, quando incorporou a proteção do meio ambiente, entendido como vetor para o bem-estar individual e social. O constituinte originário reconheceu a importância de proteção do meio ambiente como uma das esferas contidas na significação da sustentabilidade diante dos acordos internacionais. Há, nessa lógica, a existência de uma postura denominada antropocentrismo alargado, que alia a proteção da natureza (água, ar, solo, flora, etc.) para assegurar a integralidade ecológica às presentes e futuras gerações. Essa é a leitura do caput do artigo 225.

Nesse sentido, a Constituição de 1988 rompe com as correntes de desenvolvimento que visam à exploração incessável de recursos e, por meio de uma regulação protetória, instaura uma visão de desenvolvimento pautado na garantia do meio ambiente equilibrado. É possível afirmar que o constituinte dedicou-se a modular um regime jurídico voltado à manutenção e à gestão dos recursos ambientais. ${ }^{5}$ Cumpre ressaltar, ainda, que o texto constitucional elencou responsabilidades para a conservação do meio ambiente ao poder público, bem como às pessoas físicas e jurídicas, inclusive estabelecendo sanções penais e administrativas, além da reparação do dano causado. ${ }^{6}$

Após trinta anos da promulgação da Constituição de 1988, é possível analisar as implicações da inserção dos dispositivos relativos à proteção do meio ambiente no regime jurídico brasileiro, bem como quais avanços existem no que se refere ao compro- misso constitucional da sustentabilidade, especialmente na sua dimensão ambiental, perante o cenário global.

O Brasil tornou-se signatário de acordos globais que versam sobre a preservação ambiental e o desenvolvimento sustentável, tais como a ECO-92, o Protocolo de Kyoto, a Conferência Mundial Sobre o Desenvolvimento Sustentável, a Conferência de Bali, a Conferência de Copenhague, a Conferência de Clima da ONU e a Rio+20.7 Entretanto, apesar dos diversos avanços para proteção climática, desenvolvimento sustentável e preservação ambiental, os atuais posicionamentos do governo brasileiro voltam-se para uma política de exploração de recursos, muito mais do que para uma política de preservação ambiental, como é previsto na Constituição de 1988.

Recentemente, o governo brasileiro estudou possibilidades de extinção da Reserva Nacional de Cobre e Associados (Renca), o que resultaria na abertura para exploração da área localizada na Amazônia. A área englobada pela Renca é uma das mais bem preservadas da Amazônia, e a extinção da reserva atrairia o interesse de empresas de mineração, comprometendo todo o avanço na preservação da Amazônia que ocorreu desde sua criação. Não se observa - nos Poderes Executivo, Legislativo e Judiciário - a vontade institucional de se cumprir os acordos e tratados constitucionais. Não existe uma estratégia de cooperação de integração regional capaz de promover a América Latina como importante agente transformador da mentalidade de dominação manifesta, historicamente, por outros países. Todos esses fatores enfraquecem significativamente 
os esforços que culminaram em conquistas democráticas, políticas e jurídicas.

A partir desse cenário, as conquistas constitucionais, principalmente no que se refere à preservação do meio ambiente natural, nem sempre são entendidas sob o ângulo de políticas de bens comuns, como é o caso da globalização, nem por meio dos direitos da natureza, como é o caso do novo constitucionalismo latino-americano. Existem mecanismos jurídicos - como é o caso do direito ambiental (crimes ambientais, princípios ambientais) e do direito tributário (perspectivas extrafiscais, vide os créditos de carbono) - que amenizam as condutas exploratórias do homem em relação à natureza, sem, contudo, serem verificadas, por meio dessas prescrições jurídicas, alternativas capazes de trazer uma epifania sobre o lugar do ser humano na teia da vida.

Por esse motivo, os trinta anos de existência da Constituição federal servem para se rememorar a importâncias das velhas e das novas conquistas, que precisam ser entendidas sob as necessidades do momento presente, mais propriamente do século XXI. $\mathrm{O}$ significado constitucional da sustentabilidade, por exemplo, não pode se exaurir em medidas penais e administrativas, sem contemplar os impactos da relação entre homem e natureza nos próximos trinta anos. É a partir desse pressuposto que se avalia qual é a força normativa da sustentabilidade na lógica das Constituições democráticas.

\section{Fundamentos sobre a sustentabilidade e o sentido de sua dimensão jurídica}

Nos recentes escritos sobre sustentabilidade, tem-se insistido acerca da importância política, social, jurídica, ambiental/natural e econômica desse novo paradigma de vida. Estranho, pois o "novo" parece não se incorporar como obviedade de nossos dias. A sua exigência por uma nova mentalidade (VARELA, 2014, p. 48) e práticas que transformem a mente egoísta, numa perspectiva mais cooperativa, solidária e transfronteiriça, parece estar apenas naqueles livros de literatura que expõem as nossas mazelas, mas não consegue ter vida própria na realidade, sair das páginas escritas, ou seja, a narrativa constitucional, por exemplo, não difere nada da narrativa literária.

Na verdade, o que se constata é o oposto. Quando a sustentabilidade se torna uma força ideológica, capaz de se reinventar especialmente graças às engrenagens econômicas -, é impossível verificar qualquer espécie de avanço na mudança de mentalidade na qual exige a sustentabilidade. Por esse motivo, torna-se necessário esclarecer e insistir: a autorregulação da Terra - a partir das evidências termodinâmicas, químicas, físicas e biológicas - pode acelerar o desaparecimento da espécie humana, causada por nós. A interferência antropogênica na natureza é um problema político (SAAVEDRA, 2014, p. 29), cujas respostas não parecem satisfatórias desde 1972, quando aconteceu a Conferência de Estocolmo, sobre a exigência de uma racionalidade aplicada à sustentabilidade. A adoção constitucional dessa ideia se manifesta, em território brasileiro, a partir 
daquilo que o Relatório Brundtland - intitulado "Nosso Futuro Comum" - denomina como desenvolvimento sustentável.

Antes de se esboçar o desenho de um conceito operacional sobre a sustentabilidade jurídica, devem ser esclarecidos alguns fatos que permitam visualizar a necessidade dessa nova mentalidade e verificar como, muitas vezes, o direito, na sua acepção doutrinária mais comum, nem sempre tem condições de resolver as mazelas em torno do bem comum. ${ }^{8}$

Primeiro, a finitude da Terra, como já sustentado em diferentes textos, precisa ser trabalhada em dois planos: (a) no sentido físico; e (b) no sentido de que favorece o desenvolvimento da vida. Esses dois argumentos indicam o alcance e o limite da interferência humana na natureza, mas o ponto de partida será o segundo. A primeira impressão - e a mais usual - é a de que a Terra se assemelha a um corpo que vaga no espaço. Estamos nesta nave espacial sem pilotos, ou, ainda, o ser humano seria o piloto? Se o for - o que é demasiadamente improvável, mas há quem pense sob o ângulo da postura antropocêntrica -, a existência da vida, assim como sua manutenção, transformou-se numa comédia ao estilo "apertem os cintos, o piloto sumiu".

No entanto, o nosso Planeta, visto a partir do universo, incita preocupação pela sua fragilidade. Esse argumento não está todo errado, mas há um equívoco. Precisa-se distinguir o que é a Terra, entendida como superorganismo vivo, especialmente no seu aspecto físico constitutivo, e, ainda, quais elementos favorecem o desenvolvimento da vida.
Ao se visualizar a Terra como "Casa Comum" e a sua rede vital ecossistêmica, percebe-se a necessidade de o ser humano entender a sua complexidade e suas próprias características. Essa percepção e a formulação de seu entendimento não são tarefas simples, pois, a cada nova observação, a cada nova tentativa de se formular um problema de pesquisa e responder a(s) sua(s) hipótese(s), surgem outros níveis de articulação entre o observador e o fenômeno observado. $\mathrm{O}$ propósito não é retornar ao paradigma cartesiano da separação entre mente (res cogito) e matéria (res extensa) com as palavras "observador" e "fenômeno observado", mas insistir que os critérios de adaptação dos fenômenos vivos ocorrem por meio de diferentes formas de organização e estruturas (MATURANA, 2014, p. 68), que determinam quais mecanismos se tornam viáveis a ambos para que ocorram o desenvolvimento e o aperfeiçoamento da vida. Essa proposição é contemplada pela teoria da cognição de Santiago (CAPRA, 2005, p. 50).

O oxigênio, por exemplo, era altamente prejudicial à manutenção dos primeiros micróbios e seres unicelulares. Entretanto, a partir de suas mudanças estruturais e da simbiose, aos poucos, esses seres tornaram-se multicelulares e pluricelulares. A fotossíntese começou a ser gerada como fenômeno residual das cianobactérias (algas + fungos). A partir desse momento, o oxigênio passou a ser o elemento necessário à manutenção da vida.

Quanto ao primeiro argumento, proposto na letra (a), já se observa outro contraste. A resposta para a indagação: a Terra 
é frágil e finita? Seria: depende. Sim, todas as condições químicas, biológicas e termodinâmicas sofrem diferentes interferências - especialmente pelas atitudes antropogênicas -, o que causa desequilíbrio nos ciclos de regeneração e reprodução da natureza. Por esse motivo, afirma-se, de modo acertado, que se vive na Era do Antropoceno. ${ }^{9}$ No entanto, a Terra é robusta, forte, no seu sentido geofísico. Nesse caso, é possível imaginá-la como uma senhora mais forte, vide a Rainha Vitória, por exemplo. Por esse motivo, o Planeta consegue aguentar muitos impactos similares a trinta bombas atômicas e, com o tempo, regenerar-se, autorregular-se. Sem os humanos? Claro.

Diante desse cenário, o que todos esses argumentos sinalizam para se entender a importância da sustentabilidade jurídica? Primeiro, recapitula-se o conceito operacional de sustentabilidade: ${ }^{10}$ é a compreensão $e c o-$ sófica acerca da capacidade de resiliencia entre os seres e o ambiente para se determinar - de modo sincrônico e/ou diacrônico - quais são as atitudes que favorecem a sobrevivência, a prosperidade, a adaptação e a manutenção da vida equilibrada.

As palavras grifadas indicam como a racionalidade jurídica se torna pouco efetiva na proteção de um bem comum, como é a rede ecossistêmica da vida. Não obstante o argumento de que a Terra, entendida no seu significado geofísico, tem capacidade maior de resiliência, para que haja o desenvolvimento relacional entre os seres e os ambientes, ou seja, para que haja maior adaptação da vida. A sobrevivência e a manutenção termodinâmica da Terra implicam, por esse motivo, uma racionalidade da sustentabilidade, cuja matriz é um saber ecosófico, um saber dialogal entre os ramos do conhecimento. Talvez, a expressão cartesiana cogito, ergo sum deva ser substituída por: sentio et cogito, ergo sum. Essa é a premissa para se compreender a sustentabilidade no seu sentido jurídico.

As diferentes fontes normativas ${ }^{11}$ espelham os critérios - nacionais, internacionais, supranacionais e transnacionais - para se desenvolver e identificar lugares, espaços de alcance e efetividade dos comportamentos humanos na cadeia vital terrestre. O espaço do Estado-Nação já não comporta instrumentos de coerção necessários quando se trata de articulações políticas, jurídicas, econômicas, ambientais/naturais, sociais no mundo.

A jurisdição constitucional nacional não consegue, sozinha, identificar razoavelmente os autores de um dano difuso, tampouco quantificar monetariamente a extensão desse dano, para humanos ou não humanos. A tarefa se apresenta hercúlea, senão impossível, se pensada nesses parâmetros. Se as fontes normativas têm como fundamento primário um saber ecosófico, podem ser visualizados os agentes, as experiências, os locais, as estratégias e os modos de articulação para se chegar numa resposta satisfatória diante desse problema que é político, jurídico e econômico, denominado crise da sustentabilidade.

É possível, nesse primeiro momento, trazer um rol exemplificativo - nunca taxativo - daquilo que constitui possibilidades ao desenvolvimento da sustentabilidade jurídica: a) política jurídica; b) circulação de modelos jurídicos; c) direitos da natureza; d) direito (socio)ambiental; e) direito e jus- 
tiça global; f) direito à sustentabilidade; g) direitos humanos; h) direito constitucional; i) pluralismo jurídico; j) tratados, acordos e convenções internacionais; k) direito comparado; l) direito comunitário; m) jurisprudência das cortes internacionais.

A partir dessa tessitura jurídica, amparada pelo saber ecosófico, é que a promoção da sustentabilidade deixa, aos poucos, de ser ideologia de poucos, para trazer a metamorfose de um tempo, de uma utopia constitucional capaz de elevar as civilizações a outro patamar de humanidade. Não se trata, como apontado no início deste tópico, de as ideias e ideologias - novas e velhas - terem a capacidade de se reinventarem para manter os mesmos cenários de destruição, segregação, indiferença e intolerância global. A função ecológica da sustentabilidade jurídica demanda não apenas nova mentalidade, mas, também, espírito de proteção à nossa "Casa Comum", a qual se inicia desde o cotidiano das nações, assegurado pela força normativa constitucional, até a emergência de uma sociedade global dotada de vários atores, com diferentes espaços para a cooperação política e econômica.

Nesse caso, o que seria, em termos de um conceito operacional, a sustentabilidade jurídica? ${ }^{12}$ Ela é a interação entre os diferentes níveis de articulação, organização, linguagem e estrutura das fontes normativas, para assegurar os modos de desenvolvimento das vidas e de sua dignidade.

Ao se compreender as exigências de um novo tempo, que não se subordina a uma razão instrumental, tampouco aos interesses e às necessidades de nações diante de seu compromisso de responsabilidade com todos, humanos e não humanos, a sustenta- bilidade jurídica inaugura uma outra acepção das finalidades jurídicas e reafirma o seu entendimento constitucional da dignidade da vida, desde o seu significado existencial, que surge no microcosmo e se expande ao macrocosmo.

A permanente caminhada, este ir e vir entre os portões do inferno à cidade prateada celestial, na qual se entende a importância dessa rede vital ecossistêmica abrigada pela Terra. Sem essa condição, insiste-se, a sustentabilidade jurídica é apenas um nome vazio de uma vazia e pretensa convivialidade entre tudo e todos. Os retrocessos hermenêuticos em prol do critério econômico, travestidos de uma identidade constitucional, inviabilizam a efetividade dos objetivos pretendidos pela sustentabilidade em sua dimensão jurídica. Em nome da Constituição e de um mundo mais sustentável, enormes violências são realizadas para se assegurar um modus vivendi fundado no ódio, na cobiça, na miséria, na segregação. $\mathrm{O}$ horizonte do significado jurídico da sustentabilidade exige passos corajosos contra esses cenários, bem como reivindica uma outra racionalidade, na qual não se permita a transição homem ou vida considerados como "fins em si mesmos" para homem ou vida considerados como "simples instrumentos" (DARDOT; LAVAL, 2016, p. 323), descartáveis a qualquer momento.

\section{A tetradimensionalidade da}

\section{sustentabilidade na sua vertente jurídica}

A sustentabilidade, entendida, minimamente, pelo significado ambiental, econômico e social, deixa de ser simples com- 
promisso ético para se tornar, aos poucos, exigível. A convergência de interesses em prol de seus objetivos reúne as nações para a construção de mecanismos e estratégias capazes de tornar viável uma forma de convivência mais digna, desprovida ou, ao menos, mitigada daqueles interesses exclusivamente egoístas, focados na obtenção do lucro a qualquer preço. As Constituições já expressam essa atitude como indispensável ao desenvolvimento interno.

Ao se deparar com os novos fenômenos de ocorrência local, mas de alcance global como as mudanças climáticas, o problema do lixo, a exploração do trabalho alheio, a dispersão energética, a destruição dos ecossistemas -, é necessário se pensar como a Constituição federal de 1988 consegue resolver, dentro de seus limites, esses conflitos. É preciso indagar se a racionalidade jurídica, do modo como é apresentada, debatida e aplicada, acompanha as metamorfoses de um tempo histórico em transição.

Nessa era geológica denominada Antropoceno, ${ }^{13}$ não é possível que a hermenêutica constitucional permaneça míope diante das novas exigências e reivindicações que sinalizam outros modo de convivência, de reconhecimento, de atitude perante os humanos e os não humanos. A insistência de uma racionalidade estritamente burocrática apenas reforça essa cegueira - institucional, moral e vital - que exclui tudo o que não possa ser medido, descrito e quantificado pelas premissas formuladas a partir do entendimento humano.

Deve-se esclarecer uma questão pontual: o problema ecológico de nosso tempo se refere às causas antropogênicas de uma destruição global, especialmente na sua dimensão política. A prevalência de interesses que se sobressaiam à esfera do comum - nem público, nem privado - evidencia nossa imaturidade enquanto espécie. Nesse caso - e na medida que surgem novos atores mundiais para estreitar os modos de exercício e reivindicação desses outros modos de convivialidade fundados em atitudes solidárias, cooperativas, cheias de compaixão pela miséria alheia -, precisa-se identificar novos espaços compreensivos, para que a sustentabilidade não seja, insiste-se, um produto das mentalidades ideológicas hipócritas.

Dentre os temas estudados sobre esse assunto, pode-se observar o uso de instrumentos nos quais se favorece a amplitude de uma teia de interconexão entre o local e o global. $\mathrm{O}$ direito internacional privado, por exemplo, permite que haja maiores preocupação e esforço de aplicação dos tratados internacionais, principalmente pelo controle de convencionalidade. Outro caso pode ser descrito pela governança, cuja força se apresenta mais na dimensão privada do que na pública. O reconhecimento de ambos é fundamental para o acesso, o uso e o aperfeiçoamento permanentes desses instrumentos, a fim de insistir numa consciência da sustentabilidade. No entanto, é necessário, também, identificar seus limites.

$\mathrm{O}$ primeiro caso apresentado, por exemplo, reforça a necessidade - juntamente com o artigo $5^{\circ}, \S 1^{\circ}$ da Constituição federal - de aplicação daqueles tratados (bilaterais, plurilaterais, multilaterais) dos quais o Brasil é signatário. O Poder Judiciário não pode afastar a aplicação desses documentos na medida em que as suas prescrições con- 
sigam ampliar os significados da dignidade humana, especialmente no seu sentido ecológico. ${ }^{14}$ Entretanto, a legislação brasileira, assim como o direito internacional privado, tem uma estranha obsessão onfaloscópica: ${ }^{15}$ nada importa, nenhuma cooperação é maior que aquela constituída pelo espírito nacional. A partir desse argumento, não existe qualquer perspectiva de sustentabilidade que possa se tornar horizonte de existência, pois o Outro é marginalizado. O vínculo de humanidade compartilhada se fragmenta, rompe-se devido à sua fragilidade, semelhante a um castiçal de cristal. As teias comunicativas entre o local e global cessam e se incrementa a irresponsabilidade nacional ante a miséria de seus cidadãos, dos seres humanos e da própria natureza.

No segundo caso, o da governança, percebe-se sua maior efetivação devido à natureza privada. As diferentes organizações não governamentais, os tribunais de arbitragem, os movimentos sociais, entre outros, situam a importância dessa condição comunicativa entre diferentes lugares e tempos, dessa tessitura da sustentabilidade. Entretanto, a governança não deve ocorrer tão somente na dimensão privada, ela precisa se manifestar, ainda, nas esferas públicas e do comum.

Este é o desafio: enquanto, no primeiro caso - referente à governança privada -, observa-se a amplitude de atores e sua eficácia em diferentes lugares do mundo, o segundo caso é altamente restrito. A governança pública, devido ao seu uso por meio da racionalidade instrumental e burocrática, tem alcance limitado. Na verdade, o seu uso deveria auxiliar a formação da tessitura da sustentabilidade, mediá-la para que se cum- prisse tanto o texto constitucional quanto as políticas de articulação com os tratados internacionais. No entanto, pode-se observar algumas dificuldades dessa postura, como: a) pouca imparcialidade na execução de atividades que se iniciam no público, mas precisariam se estender ao comum; b) não reconhecimento das necessidades de cada época, ou seja, de se identificar a novidade no momento presente; c) aposta em uma hipérbole do futuro, esquecendo-se do presente.

As recompensas do momento presente são planejadas e enviadas ao futuro, em outras palavras, espera-se que, no futuro, os objetivos sejam alcançados. Futuro é apenas a perpetuação do momento presente. Caso essa premissa não seja clara, nenhum futuro haverá de se manifestar, especialmente com relação ao legado da integridade ecológica do mundo.

Dentro desse quadro, retoma-se a afirmação inicial deste tópico, de que a sustentabilidade é compreendida por três bases: o social, o ambiental e o econômico. O diálogo permanente entre essas esferas assegura uma primeira compreensão sobre a importância desse paradigma voltado à vida digna. Contudo, lembrando da teoria tridimensional do direito, de Miguel Reale, pode-se trazer uma quarta base: a jurídica.

$\mathrm{Na}$ medida em que outros elementos se integram ao fundamento ecológico da sustentabilidade, percebe-se que a sua racionalidade não é aquela das previsões governamentais, tampouco a da lógica estrita dos negócios internacionais, os quais admitem somente como sujeitos de direito os Estados nacionais. A racionalidade da sustentabilidade, mesmo numa perspectiva hermenêu- 
tica constitucional, é ecosófica, ou, ainda, funda-se na ecologia dos saberes. ${ }^{16}$ Nesse caso, devem ser identificadas algumas das manifestações dessas interações entre as diferentes bases que auxiliam a existência da sustentabilidade nessa tetradimensionalidade indicada pela condição jurídica.

Supondo-se que:

$\mathrm{S}(\mathrm{g})=\mathrm{Ec}(\mathrm{esp})+.\mathrm{Amb}(\mathrm{esp})+.\mathrm{Soc}$ (esp.) + Jur (esp.)

Em cada dimensão sinalizada, é possível realizar as suas combinações para se saber como desenvolver, aplicar, interpretar, elaborar os sentidos da sustentabilidade a fim de se que cumpram os seus objetivos, especialmente aqueles enunciados pelos objetivos do desenvolvimento sustentável (ODS). Nesse caso, é possível visualizar o seguinte:

$\mathrm{Ec}+\mathrm{Amb}+\mathrm{Jur}=$ direito ambiental empresarial;

$\mathrm{Ec}+\mathrm{Soc}+\mathrm{Jur}=$ justiça distributiva, justiça restaurativa, princípio da solidariedade;

$\mathrm{Ec}+\mathrm{Ec}+\mathrm{Jur}=$ law and economics;

$\mathrm{Ec}+\mathrm{Amb}+\mathrm{Soc}+\mathrm{Jur}=$ direito à sustentabilidade, princípio da sustentabilidade

$A m b+A m b+$ Jur $=$ direitos da natureza;

$\mathrm{Amb}+\mathrm{Soc}+\mathrm{Jur}=$ direito socioambiental, imaginário jurídico socioambiental, tratados internacionais e supranacionais socioambientais.
Esse é apenas um esboço inicial daquilo que se consegue identificar como matrizes jurídicas da sustentabilidade. $\mathrm{O}$ trabalho ecosófico do termo e as suas possibilidades demandam maiores estudos a fim de se determinar, também, os limites e os alcances de cada dimensão. Visualiza-se, também, novos avanços de cumprimento das exigências sustentáveis que não circundam exclusivamente o direito ambiental, o direito administrativo e o direito penal. $\mathrm{O}$ sentido jurídico da sustentabilidade, ou melhor, o sentido constitucional da sustentabilidade apresenta outros caminhos que permitem enraizar o entendimento de que nossa permanente humanização depende desta matriz relacional do homem com o mundo, que se manifesta diante de si como absoluta alteridade.

A tetradimensionalidade da sustentabilidade refere-se, tão somente, a reconhecer um dentre os diferentes campos de atuação que compõem o significado da sustentabilidade. Não é possível definir essa palavra pela quantidade de suas faces devido à conectividade em rede dos espaços existentes e que formam uma linguagem própria, bem como de outros, nos quais, historicamente, podem surgir e compor o mosaico léxico da sustentabilidade. A Constituição federal de 1988, a partir dessa afirmação, deve reconhecer os novos desafios de cada tempo, a fim de, historicamente, registrar novas conquistas, novos avanços em prol da vida digna para tudo e todos. 


\section{Conclusão}

Toda Constituição representa, além de seu sentido normativo, um projeto ético desenvolvido pelas conquistas históricas de cada sociedade acerca das necessidades e atitudes indispensáveis para a convivência harmoniosa entre as pessoas. Não obstante o registro e a exigibilidade desses direitos, nem sempre o seu conteúdo e seus mecanismos asseguram o devido cumprimento, tampouco fomentam um espírito que impulsione e perpetue mudanças que impliquem novos valores, novos direitos, novas formas de se ampliar a dimensão relacional entre os seres humanos e desses com o mundo.

É a partir dessa compreensão que se ampliam e se fortalecem, por exemplo, condições de uma vida digna, a liberdade que converge nos interesses da igualdade, e ambas são fortalecidas pela fraternidade e pela justiça. Esses são novos desafios que o tempo traz, a fim de que a Constituição seja a fotografia mais genuína do momento presente, seja pelas suas qualidades seja pelas dificuldades. A sustentabilidade, entendida na sua dimensão jurídica, especialmente constitucional, representa um marco na busca de outros valores, outras formas de sentir, pensar e agir, capazes de tornar reais as esperanças que surgem em cotidianos de indiferença, desprezo, humilhação e miséria.

Qualquer Constituição como a de 1988 já avança no sentido de prescrever esses cenários como inalienáveis, para que haja um equilíbrio necessário para a manutenção da dignidade e o reconhecimento da interdependência entre os seres. $\mathrm{O}$ agir que se manifesta pelo cuidado não tem como des- tinatário apenas outro ser humano, mas a vida no seu significado mais amplo. Por esse motivo, cabe à sustentabilidade, no sentido constitucional, ter a criatividade para enxergar o futuro no presente e elaborar as estratégias necessárias, apostando num tempo que não o é, mas que resgata todas as possibilidades de um modus vivendi desejado por todos. Essa é a tessitura da sustentabilidade, a qual favorece o cumprimento de um projeto social fundado nos direitos fundamentais.

A partir dessas afirmações, pode-se destacar que a hipótese desta pesquisa foi confirmada: a sustentabilidade, nesses trinta anos da Constituição federal de 1988, foi pioneira em reconhecer a manutenção do meio ambiente como indispensável à vida qualitativa e digna. No entanto, o século XXI exige novos imperativos éticos e jurídicos que representem a amplitude da relação entre homem e natureza. Nesse caso, a sustentabilidade traz a necessidade de outros avanços, os quais já se manifestam na América Latina. É preciso compreender o tempo e suas complexidades, para que a vida se renove perpetuamente e que a Constituição assegure o registro dessas novas conquistas em prol do viver e do conviver sempre mais sadios.

\section{Abstract}

The objective of this study is the importance of Sustainability and its legal significance in these thirty years of the Federal Constitution of 1988. It was determined, as the main objective, to demonstrate how the definition of sustainability, in its legal dimension, allows 
the historical understanding about relations between human and nonhuman and the demands for actions that undermine the improvement of this harmonic perspective. To do this research the inductive method was used. At the end of this text, it was verified that there have been advances in the application of the Constitution in its article 225, but the XXI century brings new challenges still little understood by our constitutional semantics.

Keywords: Federal Constitution of 1988. Challenges. Legal dimension. Sustainability. Thirty years.

\section{Resumen}

El objeto de este estudio trata de la importancia sobre la Sustentabilidad y su significado jurídico en esos treinta años de vigencia de la Constitución Federal de 1988. Se determinó, como objetivo general, demostrar cómo la definición de sostenibilidad en su dimensión jurídica favorece la histórica comprensión sobre las relaciones entre humanos y no humanos y la necesaria exigibilidad de acciones que perjudican el perfeccionamiento de esa perspectiva armónica. Se utilizó como método, en la fase de investigación, el Inductivo. Al final de este texto, se verificó que hubo avances en la aplicación del artículo 225 de la Constitución, pero que el siglo XXI trae nuevos desafíos aún poco comprendidos por la semántica constitucional.

Palabras clave: Constitución federal de 1988. Retos. Dimensión jurídica. Sostenibilidad. Treinta años.

\section{Notas}

1 Este artigo foi realizado com as colaborações de Diogo Dal Magro - graduando do Curso de Direito da Faculdade Meridional (Imed), membro dos grupos de pesquisa "Ética, Cidadania e Sustentabilidade" e "Latin America Privacy Hub", vinculados ao Programa de Pós-Graduação Stricto Sensu - Mestrado em Direito, da Imed, bolsista Pibic CNPq/Imed, associado da Rede Brasileira de Direito e Literatura (e-mail: diogodalmagro@ gmail.com) - e de Giulia Signor - graduanda do Curso de Direito da Imed, membro do grupo de pesquisa "Ética, Cidadania e Sustentabilidade", vinculado ao Programa de Pós-Graduação Stricto Sensu - Mestrado em Direito, da Imed (e-mail: giulia.signor@yahoo.com.br).

2 “Técnica de investigação em livros, repertórios jurisprudenciais e coletâneas legais" (PASOLD, 2018, p. 217).

3 "[...] palavra ou expressão estratégica à elaboração e/ou expressão de uma ideia" (PASOLD, 2018, p. 207).

4 "[...] definição estabelecida ou proposta para uma palavra ou expressão, com o propósito de que tal definição seja aceita para os efeitos da ideia proposta" (PASOLD, 2018, p. 207).

5 " $[\ldots]$ it is reasonable to suppose that the more that humans come to understand about the interconnectedness of their health and well-being with that nonhuman nature, the more inseparable appear their interests with the 'good' of nature" (HAYWARD, 2000, p. 34).

6 Vide artigo 225, § $3^{\circ}$ : “As condutas e atividades consideradas lesivas ao meio ambiente sujeitarão os infratores, pessoas físicas ou jurídicas, a sanções penais e administrativas, independentemente da obrigação de reparar os danos causados" (BRASIL, 1988).

7 Os acordos citados podem ser conferidos no site do governo do Brasil, disponível em: <http:// www.brasil.gov.br/editoria/meio-ambiente/2012/01/acordos-globais>. Acesso em: 15 jun. 2018.

8 "O bem comum pressupõe o respeito pela pessoa humana enquanto tal, com direitos fundamentais e inalienáveis orientados para o seu desenvolvimento integral. Exige também os dispositivos de bem-estar e segurança social e o desenvolvimento dos vários grupos intermédios, aplicando o princípio da subsidiariedade. Entre tais grupos, destaca-se de forma especial a família enquanto célula basilar da sociedade. Por fim, o bem comum requer a paz social, isto é, a estabilida- 
de e a segurança de uma certa ordem, que não se realiza sem uma atenção particular à justiça distributiva, cuja violação gera sempre violência. Toda a sociedade - e, nela, especialmente o Estado - tem obrigação de defender e promover o bem comum. Nas condições atuais da sociedade mundial, onde há tantas desigualdades e são cada vez mais numerosas as pessoas descartadas, privadas dos direitos humanos fundamentais, o princípio do bem comum torna-se imediatamente, como consequência lógica e inevitável, um apelo à solidariedade e uma opção preferencial pelos mais pobres. [...] Basta observar a realidade para compreender que, hoje, esta opção é uma exigência ética fundamental para a efetiva realização do bem comum" (FRANCISCO, 2015, p. 95).

9 Desde os anos 1980, alguns pesquisadores começaram a definir o termo Antropoceno como uma época em que os efeitos da humanidade estariam afetando globalmente nosso planeta. O Prêmio Nobel de Química (1995) Paul Crutzen auxiliou na popularização do termo nos anos 2000, por meio de uma série de publicações discutindo o que seria essa nova era geológica da Terra, na qual a influência humana se mostra presente em algumas áreas, em parceria com as influências geológicas. "A humanidade emerge como uma força significante globalmente, capaz de interferir em processos críticos de nosso planeta, como a composição da atmosfera e outras propriedades" (ARTAXO, 2014, p. 15).

10 Conceito operacional desenvolvido pelo professor doutor Sérgio Ricardo Fernandes de Aquino.

11 "Na medida em que o Direito Global contesta a hegemonia homogeneizadora do Estado nacional, típico do modelo Vestfáliano, para a produção normativa, abre uma senda para a consideração de manifestações antes marginais como jurídicas e normatizadora das dinâmicas sociais e institucionais. Nesse sentido, a proposição de fontes normativas do Direito Global decorre da Sociedade e, cumulativamente, da capacidade institucional das suas instituições no exercício da autoridade que possuem. Portanto, como primeira premissa, as fontes normativas do Direito Global surgem das plurimas instituições sociais atuantes nos cenários da globalização" (STAFFEN, 2018, p. 59).

12 Conceito operacional elaborado junto com o acadêmico Matheus Figueiredo Nunes de Souza, mestrando em Direito pelo Programa de Pós-Graduação Stricto Sensu da Imed.
13 "Poluímos o ar que respiramos, degradamos o solo que nos alimenta e contaminamos a água que bebemos. O ser humano parece não perceber que depende de uma base ecológica para a sustentação de sua vida e de seus descendentes" (DIAS, 2016, p. 10).

14 “[...] não nos parece possível excluir de uma compreensão necessariamente multidimensional e não reducionista da dignidade da pessoa humana, aquilo que poderá designar de uma dimensão ecológica [...] da dignidade humana, que, por sua vez, também não poderá ser restringida a uma dimensão puramente biológica ou física, pois contempla a vida como um todo, inclusive do ambiente em que a vida humana (mas também a não humana) se desenvolve" (FERNSTERSEIFER; SARLET, 2014, p. 47-48).

15 Essa postura, segundo Maffesoli, significa a caracterização de "[...] nossa intelligentsia: ela contempla o próprio umbigo" (2009, p. 18).

16 "A ecologia dos saberes é um conjunto de epistemologias que partem da possibilidade da diversidade e da globalização contra hegemônicas e pretendem contribuir para as credibilizar e fortalecer. Assentam em dois pressupostos: 1) não há epistemologias neutras e as que clamam sê-lo são as menos neutras; 2 ) a reflexão epistemológica deve incidir não nos conhecimentos em abstracto, mas nas práticas de conhecimento e seus impactos noutras práticas sociais. Quando falo de ecologia de saberes, entendo-as como ecologia de práticas de saberes" (SANTOS, 2006, p. 154).

\section{Referências}

ARTAXO, Paulo. Uma nova era geológica em nosso planeta: o antropoceno? Revista da USP, São Paulo, n. 103, 2014. Disponível em: <http://www.revistas.usp.br/revusp/article/view/99279>. Acesso em: 14 jan. 2018.

BRASIL. Constituição (1988). Constituição da República Federativa do Brasil: promulgada em 5 de outubro de 1988. Brasília, DF, 1988. Disponível em: <http://www.planalto.gov. br/ccivil_03/constituicao/constituicaocompilado.htm>. Acesso em: 11 abr. 2018. 
BENJAMIN, Antonio Herman de Vasconcelos E. O meio ambiente na Constituição federal de 1988. Biblioteca Digital Jurídica - BDJur. 2011. Disponível em <bdjur.stj.jus.br/dspace/bitstream/2011/8643/1/O_Meio_Ambiente_na_ Constitui\%C3\%A7\%C3\%A3o.pdf>.Acessoem: 15 jun. 2018.

CAPRA, Fritjof. As conexões ocultas: ciência para uma vida sustentável. Tradução de Marcelo Brandão Cipolla. São Paulo: Cultrix, 2005.

DARDOT, Pierre; LAVAL, Christian. A nova razão do mundo: ensaio sobre a sociedade neoliberal. Tradução de Mariana Echalar. São Paulo: Boitempo, 2016.

DIAS, Genebaldo Freire. Antropoceno: iniciação à temática ambiental. 2. ed. rev. e atual. São Paulo: Gaia, 2016.

FERNSTERSEIFER, Tiago; SARLET, Ingo Wolfgang. Princípios do direito ambiental. São Paulo: Saraiva, 2014.

IGREJA CATÓLICA. Papa (2013 -:Francisco). Carta Encíclica Laudato Si: sobre o cuidado da casa comum. São Paulo: Paulus; Loyola, 2015.

HAYWARD, Tim. Constitucional enviromental rights. New York: Oxford University Press, 2000.

LEFF, Enrique. Saber ambiental: sustentabilidade, racionalidade, complexidade, poder. Tradução de Lúcia Mathilde Endlic Orth. 11. ed. Petrópolis: Vozes, 2015.

MAFFESOLI, Michel. A república dos bons sentimentos. Tradução de Ana Goldberger. São Paulo: Iluminuras; Itaú Cultural, 2009.

MATURANA, Humberto. O que se observa depende do observador. In: THOMPSON, William (Org.). Gaia: uma teoria do conhecimento. Tradução de Silvio Cerqueira Leite. 4. ed. São Paulo: Gaia, 2014. p. 60-85.

PASOLD, Cesar Luiz. Metodologia da pesquisa jurídica: teoria e prática. 14. ed. rev. atual. e ampl. Florianópolis: Empório Modara, 2018.
SAAVEDRA, Jaime Fernando Estenssoro. História do debate ambiental na política mundial 19451992: a perspectiva latino-americana. Tradução de Daniel Rubens Censi. Ijuí: Editora da Unijuí, 2014.

SANTOS, Boaventura de Sousa. A gramática do tempo: para uma nova cultura política. São Paulo: Cortez, 2006.

STAFFEN, Márcio. Interfaces do direito global. 2. ed. Rio de Janeiro: Lúmen Juris, 2018.

VARELA, Francisco. O caminhar faz a trilha. In: THOMPSON, William (Org.). Gaia: uma teoria do conhecimento. Tradução de Silvio Cerqueira Leite. 4. ed. São Paulo: Gaia, 2014. p. 120-167. 